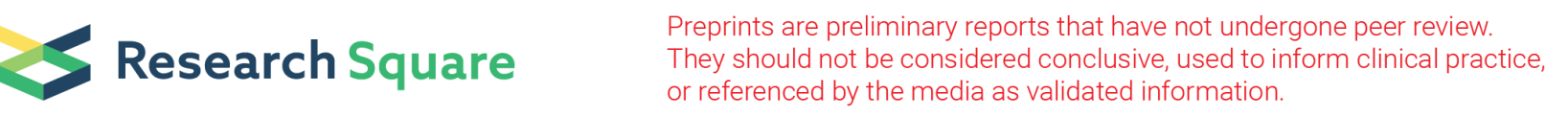

\title{
Based on bioinformatics studies on the effect of alpha1H on key genes, pathways in bladder cancer and IncRNA on patient prognosis
}

Haiyong Zhou ( $\sim$ zhy821101@163.com )

Zhejiang Hospital

\section{Xing Wang}

Zhejiang Hospital

Jiandi Yu

Zhejiang Hospital

Kun Peng

Zhejiang Hospital

\section{Huali Wen}

Zhejiang Hospital

\section{Renjie Wang}

Zhejiang Hospital

\section{Research Article}

Keywords: alpha1H, bladder cancer, prognosis

Posted Date: March 28th, 2022

DOl: https://doi.org/10.21203/rs.3.rs-1198370/v2

License: (9) (i) This work is licensed under a Creative Commons Attribution 4.0 International License.

Read Full License 


\section{Abstract}

Objective: To analyze the differential genes, IncRNA, signaling pathway and patient prognosis of bladder cancer after alpha1 $\mathrm{H}$ treatment.

Methods: Sequencing data GSE172112 for patients in clinical trials with a new bladder cancer drug were downloaded from the GEO database, The bladder cancer tissues using the new drug alpha1 $\mathrm{H}$ (alpha1oleate) and placebo (placebo) were analyzed in the R language, The differentially expressed genes were selected; Differential genes were analyzed for KEGG pathway enrichment using the DAVID database, To explore the effect of a Ipha1 $\mathrm{H}$ treatment on pathways in patients with bladder cancer; at the same time, IncRNA expression data from the Bladder Cancer (BLCA) dataset were also downloaded through the TCGA database, First, screening for differential IncRNA expression, The screening results were then analyzed by univariate Cox regression to initially screen for IncRNA associated with prognosis, The key IncRNA affecting the prognosis were further screened out, The prognostic model was also constructed using multivariate Cox regression analysis.

Results: There yielded 394 significantly upregulated genes and 385 significantly downregulated genes in bladder cancer tissue after alpha $1 \mathrm{H}$ treatment. Through gene signaling pathway enrichment analysis, the upregulated genes were mainly enriched in the signaling pathways regulating the pluripotent line of stem cell cells, the TGF-signaling pathways, and the cell cycle. The downregulated genes were mainly enriched in the MAPK signaling pathway, phagosomes, and the TNF signaling pathway. After alpha1H treatment, of 119 differentially expressed IncRNA, from the Inc2cancer database, two genes were found to be potentially associated with bladder cancer prognosis, and the final analysis confirmed the key IncRNA affecting prognosis. The results of survival analysis showed that high expression of LINC00152 unfavorable unfavorable patient prognosis and the new drug alpha1H reduces LINC00152 favors patient prognosis.

Conclusion: Alpha1 $\mathrm{H}$ can cure bladder cancer by regulating hallmark signaling, TGF-beta signaling, and LINC00152.

\section{Background}

Bladder cancer (Bladder cancer, BC) is a common malignancy in the male genitinary system, and a 2018 global cancer statistics reported that the incidence of $\mathrm{BC}$ was $4.5 \%$ in men and a mortality rate of $2.8 \%$

${ }^{[1]}$.The main clinical presenting symptom of $\mathrm{BC}$ is hematuria ${ }^{[2]} .90 \%$ of $\mathrm{BC}$ occurrence is caused by the malignant proliferation of urothelial cells, most of which are located in the bladder ${ }^{[3]}$. BC can be classified into non-muscle-invasive bladder cancer and muscle-invasive bladder cancer ${ }^{[2]}$.Currently, more than $80 \%$ of bladder tumors are non-muscle-invasive papillary tumors, and although their 5-year survival rate is $90 \%$, approximately $70 \%$ of these patients will relapse ${ }^{[4]}$. 
In 2002, BCG first reported the effective use of BCG in the treatment of superficial BC by Morales et $\mathrm{al}^{[5]}$.During the subsequent decades, the researchers made great clinical progress in treating $\mathrm{BC}$ by surgical resection, chemotherapy, and immunocheckpoint inhibitors. Transurethral bladder tumor resection is often used clinically for the treatment of non-muscle-invasive bladder cancer ${ }^{[6]}$.Platinumbased chemotherapy is often used for patients with muscle-invasive bladder cancer ${ }^{[7]} \cdot$ In 2020 , the European Urology Guidelines Association reported on treatment for muscle invasive and metastatic bladder cancer, they clearly stated that cisplatin-based chemotherapy remains preferred in patients with BC metastatic. Secondly, immunotherapy is recommended for patients positive for programmed death ligand 1 (PD-L1), or with carboplatin for PD-L1-negative patients. For second-line therapy of BC metastatic disease, Pymtuzumab therapy is recommended ${ }^{[8]}$.It is well known that immunotherapy has better effects and less side effects compared with the strong toxic side effects and high recurrence rate of traditional chemotherapy therapy. In recent years, despite the success of immunosuppressive therapy in $\mathrm{BC}$, the objective response to immunosuppressive monotherapy remains within the $20 \%$ range, suggesting a lower response to immunotherapy in some patients ${ }^{[9]}$. Therefore, developing a less toxic antitumor complex for $\mathrm{BC}$ would be very popular. Human milk albumin is flexible and able to form stable protein-fatty acid complexes with fatty acids. Among them, the alpha1-oleate generated by its binding to oleic acid has been confirmed by many researchers to have antitumor effects. It has been shown that alpha1H shows better therapeutic effects in the mouse MB49 bladder cancer model ${ }^{[10]}$.In an animal study, mice found a dose-dependent reduction in tumor size, bladder size and bladder weight in alpha $1 \mathrm{H}$ treated mice compared to the counterfeit drug group, and increased alpha1 $\mathrm{H}$ dose had no toxic side effects on healthy tissues ${ }^{[6]}$.In a single-center, placebo-controlled, double-blind phase I / II interventional clinical trial of nonmuscle invasive bladder cancer, the infusion of alpha1H in the bladder resulted in massive cell loss of tumor cells, smaller tumors, apoptosis after treatment, and suppressed expression of cancer-related genes ${ }^{[11]}$.

As bioinformatics developed, researchers found that IncRNA expression is closely related to tumor genesis and progression ${ }^{[12]}$. This suggests that IncRNA can serve as a tumor biomarker as well as as a therapeutic target. In recent years, many studies have found IncRNA to be associated with the diagnosis and prognosis in BC patients. Li Gang et al ${ }^{[13]}$ found that IncRNA TUC338 expression was upregulated in early $B C$ patients and showed early diagnostic value. After surgical resection of the BC tumours, the plasma IncRNA TUC338 levels were significantly downregulated.Luo Huarong et al ${ }^{[14]}$ found that plasma IncRNA CASC11 was upregulated in early BC patients as compared with healthy controls.MA ZHIPENG et $\mathrm{al}^{[15]}$ found that IncRNA SNHG5 was upregulated in BC tissues and promoted BC cell proliferation by targeting $\mathrm{p} 27$, which subsequently had adverse effects on patient prognosis. In addition, Incrna UCA1 was found in a meta-analysis to be a diagnostic biomarker for $\mathrm{BC}^{[16]}$.

In this study, we screened differential genes for $\mathrm{BC}$ patients after alpha1H treatment and placebo-treated $\mathrm{BC}$ patients, $\mathrm{BC}$ patients and placebo-treated $\mathrm{BC}$ patients, followed by KEGG signaling enrichment 
analysis of the above differential genes, and confirmed prognostic key LncRNA for alpha1H treatment of bladder cancer.

\section{Methods}

\subsection{Data collection and preprocessing}

We are working from the GEO (https: // www.ncbi.nlm.nih.Sequencing data from patients with clinical trials of a new bladder cancer drug were collected in the gov / geo /) database, GSE172112, in which some patients used the new drug alpha $1 \mathrm{H}$, some patients used placebo, including several tissues using the new drug alpha1H, and several tissues using placebo. We are also quoted from the UCSC Xena (https://rowser.The Bladder Cancer (BLCA) dataset from the TCGA plan was collected and downloaded from the net / datapages /) database, including the gene RNA-seq sequencing results (after quantile standardization) of the sample, and the clinical information of the patient. In addition, we also from TANRIC (https:// www.tanric. RNA-seq Level 2 data and their clinical information from the Bladder Cancer (BLCA) dataset were collected and downloaded from the org) database, with total case samples, where several were organized after the new drug alpha1 $\mathrm{H}$ and several after placebo .

The TCGA database provides the raw counts and $\mathrm{E} n \mathrm{t} r \mathrm{z}$ e I $\mathrm{D}$ for the RNA-seq Level 2 mRNA. The annotation of the most complete human IncRNA was included and analyzed in the GENCODE v7 database, and the IncRNA dataset is more comprehensive than other databases. According to the chromosomal location of the exon provided by the TCGA database, the raw counts, and the reads number per thousand base from the map to the exon in the reads per 1 million map (reads per kilobase of exon per million mapped reads, RPKM) Information, Alignment to the chromosomal locations of the IncRNA in the GENCODE v7 database, If the chromosome position, the information is consistent, The exon is defined as a IncRNA. Using the R package "DESeq2", we transformed the read count values of the raw sequencing data into the gene expression values fit by the "DESeq2" package, and used the R package "biomaRt" to classify the detected RNA molecules into PCG (Protein Coding Gene) as well as IncRNA classes.

\subsection{Gene differential expression analysis}

For the gene expression dataset for new drug treatment, GSE172112, we divided the patient's medication profile into two groups, one using the new drug alpha1 $\mathrm{H}$ and the other using a placebo. The data chips in the gene expression data profiling were normalized in R 3.6.1 using the limma software package, Screening for differentially expressed genes, The Fold Change values were calculated, follow, Differential expression analysis was performed using the Wilcoxon rank-sum test, Record the test p-value, I FC (fold change) | 2 and $P<0.01$ were used as screening criteria for differential genes.

\subsection{KEGG pathway enrichment analysis}

DAVID 6.8 database (https://david.ncifcrf.The gov /) is a commonly used database for gene enrichment and functional annotation analysis. The KEGG pathway was analyzed for the differentially expressed 
genes using DAVID. The selection conditions were: human gene, $\mathrm{P}<0.05$.

\subsection{GSVA pathway difference analysis}

To assess the impact of new drug use on overall pathway activation in patients, we obtained from the MsigDB database (http://www.gsea-msigdb.org/gsea/index.Gene sets for downloading 50 hallmark signaling pathways were collected in jsp).Using the "ssgsea algorithm" in the R package "GSVA", combined with a gene set of 50 hallmark signaling pathways, we scored pathway activation for each sample and subsequently scored difference comparison using Wilcoxon's rank-sum test.

\subsection{Screening of the L ncRNA}

Transcripptomic sequencing data of $B C$ and detailed clinical data of $B C$ patients were downloaded from the TCGA database, Expression matrix of the long-chain non-coding RNA data was extracted from the transcriptome sequencing data; The threshold was set as a corrected $\mathrm{P}<0.05$ with a differential expression multiple $>4$ (FDR $<0.05$ and | $\log F C \mid>2$ ), Differentially expressed IncRNA were screened using the R software edgeR package, The expression data of the Inc RNA were merged with the downloaded survival data, The Inc RNA related to patient outcome after alpha1H treatment was screened by univariate Cox regression analysis; LASSO (Least Absolute Shrinkage and Selection Operator through the glmnet package and the survival package in R, LASSO) Regression analysis screening for Inc RNA with more critical prognosis with alpha1H treatment. Finally, the Inc RNA model associated with BC prognosis after alpha1 $\mathrm{H}$ treatment was established by multivariate Cox regression analysis. $\mathrm{K}-\mathrm{M}$ survival analysis was performed on IncRNA with statistically differences in Cox multivariate regression analysis to determine prognostic biomarkers.

\section{6 survival analysis}

To assess the impact of gene expression on patient prognosis, we combined the cox proportional hazards survival model in TCGA BLCA patients using the R package "survival" and performed log-rank test, record $\mathrm{HR}[95 \% \mathrm{Cl}]$ of survival model and test $\mathrm{p}$-values to assess the prognostic value of genes. Kaplan-Meier curves were drawn for the genes, IncRNA using Graphpad Prim 7 statistical software and whether statistical differences between the two groups were determined by Log-rank test, considered by $P<0.05$ as statistically significant.

\section{Results}

\section{1 alpha1H treatment affects protein-coding gene expression in patients with bladder cancer}

We collected gene expression sequencing data from clinical experimental patients with alpha1 $\mathrm{H}$, a new bladder cancer drug, GSE172112, with simple preliminary preprocessing and statistics, in which 39 patients using the new drug and 42 patients using placebo were tested, and gene expression data from a total of 81 samples were tested. Subsequently, using the R package "DESeq2", we transformed the gene 
read count data detected by the samples into the corresponding expression values, combined with the RNA classification information in the R package "biomaRt" package, yielding a total of 20,356 PCG and 12,382 IncRNA (including 7,109 lincRNA and 5,273 antisense).

First, for 20,356 protein-coding genes, using the patient drug profile, we performed differential expression analysis between patients using the new drug alpha1 $\mathrm{H}$ versus patients using placebo. We counted the mean expression of each protein-coding gene in both patient groups, calculated the corresponding FC values, and recorded the Wilcoxon rank-sum test p-values, finally obtaining 781 differentially expressed genes with a p-value $<0.01$, containing 396 significantly up-regulated genes and 385 significantly downregulated genes (Table 1, Fig. 1).

Table 1

396 KEGG pathway associated with significantly upregulated genes

\begin{tabular}{|lll|}
\hline Term & Count & PValue \\
\hline hsa 04550:Signaling pathways regulating pluripotency of stem cells & 10 & $3.52 \mathrm{E}-04$ \\
\hline hsa 04350:TGF -beta signaling pathway & 6 & 0.010437931 \\
\hline hsa 04110:Cell cycle & 7 & 0.013608859 \\
\hline hsa 03018:RNA degradation & 5 & 0.033388814 \\
\hline hsa 03420:Nucleotide excision repair & 4 & 0.037922436 \\
\hline hsa 00280:Valine, leucine and isoleucine degradation & 4 & 0.037922436 \\
\hline hsa 04330:Notch signaling pathway & 4 & 0.039997665 \\
\hline
\end{tabular}

Furthermore, we distributed differentially expressed protein-coding genes to functionally annotated significantly up-and significantly down-regulated genes.among, For the 394 genes that were significantly upregulated, We found that their function is mainly associated with the following KEGG pathway: "hsa04550: Signaling pathways regulating pluripotency of stem cells" regulates signaling in stem cells, "hsa04350: TGF-beta signaling pathway" TGF-beta signaling pathway, "hsa04110: Cell cycle" cell cycle, et al. (Table 1, Fig. 2).

But for the 385 significantly downregulated genes, we found that their function was mainly with (Table 2,Fig. 3). like the following KEGG pathway-associated: "hsa 04010:MAPK signaling pathway" MAP K signaling pathway, "hsa04145:Phagosome" phagosomal, "hsa04668:TNF signaling pathway" TNF signaling pathway 
Table 2

KEGG pathway associated with 385 significantly downregulated genes

\begin{tabular}{|lll|}
\hline Term & Count & PValue \\
\hline hsa 05132:Salmonella infection & 10 & $1.45 \mathrm{E}-04$ \\
\hline hsa 04010:MAPK signaling pathway & 15 & 0.002761576 \\
\hline hsa 05152:Tuberculosis & 12 & 0.00324906 \\
\hline hsa 04145:Phagosome & 10 & 0.009423262 \\
\hline hsa 04060:Cytokine -cytokine receptor interaction & 13 & 0.013038165 \\
\hline hsa 04668:TNF signaling pathway & 8 & 0.013680707 \\
\hline hsa 04910:Insulin signaling pathway & 9 & 0.017016212 \\
\hline hsa04064:NF-kappa B signaling pathway & 7 & 0.017281951 \\
\hline hsa 04062:Chemokine signaling pathway & 10 & 0.033343318 \\
\hline hsa 05146:Amoebiasis & 7 & 0.040529418 \\
\hline hsa 04621:NOD -like receptor signaling pathway & 5 & 0.043877413 \\
\hline hsa 05020:Prion diseases & 4 & 0.046418919 \\
\hline
\end{tabular}

\section{2 alpha1H treatment affects IncRNA expression in patients with bladder cancer}

In addition, for the non-coding RNA molecule IncRNA, the protein detected in the GSE172112 dataset, we also performed a differential expression analysis. As with the analysis of protein-coding genes, for 12,382 IncRNA, we finally obtained 119 significantly differentially expressed IncRNA, including 53 significantly upregulated IncRNA and 66 significantly downregulated IncRNA (Table 2, Fig. 4).

Further, we obtained from the Inc2cancer database (http: / / bio-

bigdata.hrbmu.edu.cn/Inc2cancer/index.The 369 bladder cancer-related IncRNA entries were downloaded from html) and two of these IncRNA were closely associated with bladder cancer and LINC00152 with TUG1 (Table 3). We found that both IncRNA were upregulated in bladder cancer patients in most literature reports, and in the GSE172112 dataset, we also compared the expression of patients using new drugs and placebo.

Table 3. Related information of LINC00152 and TUG1 recorded in Inc2Cancer database 


\begin{tabular}{|c|c|c|c|c|}
\hline IncRNA & Cancer.name & Methods & Expression.pattern & Pubmed.ID \\
\hline LINC00152 & $\begin{array}{l}\text { gallbladder } \\
\text { cancer }\end{array}$ & $\begin{array}{l}\text { qPCR, RNAi, Western blot, RIP, } \\
\text { Luciferase reporter assay etc. }\end{array}$ & up-regulated & 28077595 \\
\hline LINC00152 & $\begin{array}{l}\text { gallbladder } \\
\text { cancer }\end{array}$ & $\begin{array}{l}\text { qPCR, RNAi, Western blot, ChIP, } \\
\text { Luciferase reporter assay, Cell } \\
\text { proliferation assay etc. }\end{array}$ & up-regulated & 27829993 \\
\hline LINC00152 & $\begin{array}{l}\text { bladder } \\
\text { cancer }\end{array}$ & qRT -PCR, ect . & down-regulated & 29988223 \\
\hline TUG1 & $\begin{array}{l}\text { bladder } \\
\text { cancer }\end{array}$ & $\begin{array}{l}\text { qPCR, Luciferase reporter assay, } \\
\text { Western blot }\end{array}$ & up-regulated & 30925453 \\
\hline TUG1 & $\begin{array}{l}\text { bladder } \\
\text { cancer }\end{array}$ & $\begin{array}{l}\text { qPCR, Western blot, in vitro } \\
\text { knockdown }\end{array}$ & up-regulated & 31308746 \\
\hline TUG1 & $\begin{array}{l}\text { gallbladder } \\
\text { cancer }\end{array}$ & $\begin{array}{l}\text { qPCR, RNAi, Western blot, } \\
\text { Luciferase reporter assay, Cell } \\
\text { proliferation assay etc. }\end{array}$ & up-regulated & 28178615 \\
\hline TUG1 & $\begin{array}{l}\text { bladder } \\
\text { cancer }\end{array}$ & $\begin{array}{l}\text { qPCR, RNAi, Western blot, RIP, } \\
\text { Luciferase reporter assay etc. }\end{array}$ & up-regulated & 26318860 \\
\hline TUG1 & $\begin{array}{l}\text { bladder } \\
\text { cancer }\end{array}$ & qPCR etc. & up-regulated & 29029461 \\
\hline TUG1 & $\begin{array}{l}\text { bladder } \\
\text { cancer }\end{array}$ & $\begin{array}{l}\text { qRT -PCR, Luciferase reporter } \\
\text { assay, in vitro knockdown }\end{array}$ & up-regulated & 29321088 \\
\hline TUG1 & $\begin{array}{l}\text { bladder } \\
\text { cancer }\end{array}$ & qPCR, Western blot, MIT & up-regulated & 28503069 \\
\hline TUG1 & $\begin{array}{l}\text { bladder } \\
\text { cancer }\end{array}$ & qPCR, Western blot etc. & up-regulated & 28376901 \\
\hline TUG1 & $\begin{array}{l}\text { bladder } \\
\text { cancer }\end{array}$ & qPCR, RNAi, MTT assay etc. & up-regulated & 27460088 \\
\hline
\end{tabular}

For LINC00152, we found that the mean expression was 5.8159 in patients using new drugs, compared to 6.5003 in placebo patients and a Wilcoxon test p-value of 0.0038 , showing that LINC00152 expression was significantly reduced by using new drugs.

But for TUG1, we found that the mean expression was 12.3502 in patients with new drugs, but 12.0904 in placebo, and a Wilcoxon test p-value of 0.001 , showing that using new drugs could not reduce TUG1 expression.

Combined with the two IncRNA analysis described above, we suggest that the new drug alpha1H most likely caused a series of gene expression changes by reducing LINC00152 expression and ultimately played a good role in killing tumor cells. 


\section{3 alpha1 $\mathrm{H}$ treatment altered part of the hallmark pathway activation in patients with bladder cancer}

Using differential expression analysis between the two classes of patients in GSE172112, we found that many differentially expressed genes were generated in alpha1H-treated patients, and that treatment of alpha1 $\mathrm{H}$ at a single gene level had a huge effect on patient gene expression. Further, we evaluated whether both types of patients have a huge impact on the activation of certain pathways from the perspective of the overall pathways.

Therefore, we collected and collated gene members of the 50 hallmark pathways from the MsigDB database, rated each sample in GSE172112 for pathway activation using the "ssgsea" algorithm in the R package "GSVA", and assessed score differences between samples using the Wilcoxon rank-sum test.final, We found that in alpha $1 \mathrm{H}$ treatment compared with placebo, Activation of the following pathways in patients: where "REACTIVE_OXYGEN_SPECIES_PATHWAY", "P53_PATHWAY", "UV_RESPONSE_UV", "HYPOXIA", "APOPTOSIS", "TNFA_SIGNALING_VIA_NFKB", "COMPLEMENT", "IL6_JAK_STAT3_SIGNALING", "INFLAMMATORY_RESPONSE" is all downregulated (Table 4). 
Table 4

Differences in SSGSEA scores of 50 hallmark pathway activation in patients in the GSE172112 dataset

\section{Hallmark pathway}

REACTIVE_OXYGEN_SPECIES_PATHWAY

P53_PATHWAY

UV_RESPONSE_UP

HYPOXIA

APOPTOSIS

TNFA_SIGNALING_VIA_NFKB

COMPLEMENT

IL6_JAK_STAT3_SIGNALING

INFLAMMATORY_RESPONSE

MTORC1_SIGNALING

HEME_METABOLISM

KRAS_SIGNALING_UP

IL2_STAT5_SIGNALING

PI3K_AKT_MTOR_SIGNALING

ALLOGRAFT_REJECTION

COAGULATION

CHOLESTEROL_HOMEOSTASIS

ANDROGEN_RESPONSE

UNFOLDED_PROTEIN_RESPONSE

NOTCH_SIGNALING

INTERFERON_GAMMA_RESPONSE

ESTROGEN_RESPONSE_LATE

PROTEIN_SECRETION

EPITHELIAL_MESENCHYMAL_TRANSITION

GLYCOLYSIS

APICAL_SURFACE

\section{mean ssGSEA in}

alpha1H treated

1.569619674

1.507696636

1.424304396

1.42652941

1.531946053

1.428124292

1.374210535

1.33525268

1.281653791

1.607157413

1.405351602

1.341771721

1.40733034

1.536935306

1.30101474

1.247726476

1.492168982

1.610609182

1.587649281

1.483836676

1.49277404

1.413869042

1.708610457

1.409575339

1.437199485

1.298814008 mean ssGSEA in

placebo treated

$1.582734513 \quad 0.004120032$

1.521012228

0.007985337

0.012893519

1.434798911

0.021327705

1.439254409

1.544429318

0.02244453

1.465793485

0.023021538

1.397833555

0.033326204

0.036656563

1.368464526

0.04728863

1.317457585

1.616700174

0.050597275

0.063037602

0.067223154

0.076272281

0.103223941

0.115903328

0.122681092

1.260215792

0.158421731

0.172916472

0.178980994

1.593578296

0.185200472

1.479281759

0.198110796

1.513236111

0.201437702

1.418128337

1.70515225

0.211659698

1.432730605

0.211659698

1.443256898

0.222247114

1.308220393

0.22951047 


\begin{tabular}{|c|c|c|c|}
\hline Hallmark pathway & $\begin{array}{l}\text { mean SsGSEA in } \\
\text { alpha1H treated }\end{array}$ & $\begin{array}{l}\text { mean SsGSEA in } \\
\text { placebo treated }\end{array}$ & $\begin{array}{l}\text { wilcox.test } \\
\text { pValue }\end{array}$ \\
\hline ESTROGEN_RESPONSE_EARLY & 1.455088631 & 1.457645328 & 0.244534355 \\
\hline APICAL_JUNCTION & 1.368342672 & 1.377967747 & 0.260227498 \\
\hline ANGIOGENESIS & 1.364058543 & 1.37392876 & 0.293644881 \\
\hline ADIPOGENESIS & 1.542517571 & 1.547454615 & 0.344052034 \\
\hline XENOBIOTIC_METABOLISM & 1.318189564 & 1.322982168 & 0.404902132 \\
\hline MYOGENESIS & 1.206300049 & 1.219144025 & 0.41562863 \\
\hline INTERFERON_ALPHA_RESPONSE & 1.54320002 & 1.557834653 & 0.421053516 \\
\hline SPERMATOGENESIS & 1.002492991 & 0.99673011 & 0.437572636 \\
\hline KRAS_SIGNALING_DN & 0.920369019 & 0.915648732 & 0.531644659 \\
\hline PANCREAS_BETA_CELLS & 0.889961293 & 0.886293012 & 0.550346464 \\
\hline E2F_TARGETS & 1.457823735 & 1.450085836 & 0.569362912 \\
\hline HEDGEHOG_SIGNALING & 1.276771876 & 1.278887994 & 0.60829904 \\
\hline G2M_CHECKPOINT & 1.461654487 & 1.454182453 & 0.614900788 \\
\hline PEROXISOME & 1.456106141 & 1.454807063 & 0.731490581 \\
\hline TGF_BETA_SIGNALING & 1.616556225 & 1.614138978 & 0.752815594 \\
\hline UV_RESPONSE_DN & 1.540834642 & 1.541525932 & 0.803279015 \\
\hline MITOTIC_SPINDLE & 1.536838934 & 1.533410379 & 0.81785756 \\
\hline OXIDATIVE_PHOSPHORYLATION & 1.64021922 & 1.642747538 & 0.832498667 \\
\hline MYC_TARGETS_V1 & 1.729433959 & 1.728475121 & 0.84719746 \\
\hline BILE_ACID_METABOLISM & 1.267742379 & 1.267085055 & 0.884164318 \\
\hline WNT_BETA_CATENIN_SIGNALING & 1.378224136 & 1.378829549 & 0.966262551 \\
\hline DNA_REPAIR & 1.496350045 & 1.498487779 & 0.996250303 \\
\hline FATTY_ACID_METABOLISM & 1.464107524 & 1.464935918 & 0.996250303 \\
\hline MYC_TARGETS_V2 & 1.488252701 & 1.486866857 & 1 \\
\hline
\end{tabular}

Based on the above results, we found that the downregulation of "P53_PATHWAY" indicates the decreased proliferation capacity of tumor cells; while "TNFA_SIGNALING_VIA_NFKB", "IL6_JAK_STAT3_SIGNALING" and "INFLAMMATORY_RESPONSE" pathways indicate the alleviated 
immunoinflammatory response in patients after using the new drug alpha1 $\mathrm{H}$, indicating the removal of tumor cells (Fig. 5).

\section{4 alpha1H and the TGF-beta signaling pathway}

Combined with single gene-level differential analysis of overall pathway activation, we found that alpha1H affected some of gene members in TGF-beta signaling (including SMAD4, ACVR1C, ID4, SMAD9, SMAD6 and ACVR2B), but the activation of overall TGF-beta signaling was not significantly changed with Wilcoxon rank sum test p-value of 0.7528. However, SMAD4, SMAD9, SMAD6 Three SMAD family members also have important effects on TGF-beta signaling. Therefore, we focused on the expression of these three genes and found that all three SMAD family members were relatively highly expressed (Table 5) in patients treated with alpha1 $\mathrm{H}$.

Table 5

Expression of SMAD4, SMAD9, and SMAD6 in the GSE172112 dataset

\begin{tabular}{|lllll|}
\hline gene & $\begin{array}{l}\text { mean expression in } \\
\text { alpha1H treated }\end{array}$ & $\begin{array}{l}\text { mean expression in } \\
\text { placebo treated }\end{array}$ & FC & $\begin{array}{l}\text { wilcox.test } \\
\text { pValue }\end{array}$ \\
\hline SMAD9 & 8.654020345 & 7.850127802 & 1.102405026 & 0.003750499 \\
\hline SMAD6 & 7.889000669 & 7.319214986 & 1.077847923 & 0.006899118 \\
\hline SMAD4 & 11.30312093 & 11.10285469 & 1.018037366 & 0.006899118 \\
\hline
\end{tabular}

To further validate the role of these three genes in patients with bladder cancer, we performed a prognostic analysis of these three genes separately, combined with the expression of BLCA patients in the TCGA program and the recorded clinical prognostic information. Among them, a total of 426 patients with detected expression and clinical prognostic information were analyzed.

For SMAD4, we divided patients into high expression groups (expression above 85.0865) and low expression group (expression below 85.0865), and the HR [95\% Cl] was 1.818[1.221-2.706] and the logrank test $p$-value of 0.0029 , indicating that the worse the prognosis of SMAD4 expression (Fig. 6).

For SMAD6, we divided patients into high expression groups (expression above 34.2596) and low expression groups (expression below 34.2596), and the HR of Cox proportional hazards [ $95 \% \mathrm{Cl}$ ] of the final constructed proportional hazards model was 0.5052[0.3783-0.6747], and the log-rank test p-value< 0.0001, indicating lower SMAD6 expression (Fig. 7).

For SMAD9, we divided the patients into high expression groups (expression above 11.3209) and low expression group (expression below 11.3209) according to their expression value, and the HR [95\% $\mathrm{Cl}$ ] of the final constructed Cox proportional-risk model was 1.521 [1.064-2.174], and the log-rank test p-value was 0.021 , indicating that the worse the prognosis of patients with higher SMAD9 expression (Fig. 8). 
The above results show that the upregulation of SMAD6 gene expression after alpha1H treatment contributes to patient prognosis, but the upregulation of SMAD4 and SMAD9 genes is instead unfavorable to patient prognosis.

\subsection{LINC00152 and patients with bladder cancer}

In the analysis of differentially expressed IncRNA in the GSE172112 dataset, we found significantly downregulated LINC00152 expression in patients treated with alpha1H, and the results collected in the Inc2cancer database also showed generally high expression of this IncRNA in bladder cancer patients, we used this IncRNA to assess the prognostic value using the TCGA BLCA dataset, A total of 252 patients who examined IncRNA expression and recorded clinical prognostic information were analyzed.

We found that, given as the expression values of the LINC00152, Patients were divided into high expression groups (expression above 1.130234) and low expression groups (expression below 1.130234), The HR [95\% Cl] of the final constructed model of the Cox scale analysis was 3.681[1.354-10.01], The log-rank test p-value was 0.0062 , It shows that the high expression of LINC00152 is unfavorable to the patient prognosis, The new drug alpha1H reduces LINC00152 and has a positive effect on curing cancer (Fig. 9).

\section{Discussion}

In this study, by comparing the $\mathrm{BC}$ tissues after alpha1 $\mathrm{H}$ treatment and after placebo treatment, a total of 781 differential genes were selected, including 396 upregulated genes and 385 downregulated genes. Upregulated genes are mainly involved in seven pathways, including the signaling pathway regulating stem cell pluripotency, TGF-signaling pathway, cell cycle, RNA degradation, nucleotide excision repair, valine, leucine, and isoleucine degradation, and Notch signaling pathway. The downregulated genes are mainly involved in 12 pathways, including Salmonella infection, MAPK signaling, pulmonary tuberculosis, phagosomes, cytokine receptor interactions, tumor necrosis factor signaling, insulin signaling, NF-B signaling, chemokine signaling, amoebosis, NOD-like receptor signaling, and prion disease. Signaling pathways associated with bladder cancer (BC) progression may be important targets for systemic therapy. Manal Elmasry et al ${ }^{[17]}$ found that mitogen-activated protein kinase (MAPK / ERK) signaling is associated with $\mathrm{BC}$ progression, and the results showed that MAPK signaling can control BC cell activity, and that inhibition of M A P C signaling in BC xenografts would inhibit BC cell growth and reduce BC cell subsets. In this study, the genes significantly downregulated after treatment with the new drug alpha1H were associated with MAPK signaling.

In this study, we found that alpha1H can have a positive effect on the prognosis of $\mathrm{BC}$ through intervention in related signaling pathways, mainly including P53 signaling, IL-6 / Stat3 signaling, TNF- / NF-B signaling, etc.YE GUOMEl et al 26 found that puerurin inhibited bladder cancer T24 cell proliferation

and induced apoptosis by inhibiting the SIRT1 / p53 signaling pathway. Jelena Korac-Prlic et al ${ }^{[18]}$ found 
that blocking the IL-6 / Stat3 axis alone inhibits bladder cancer progression.Chen Jia-Liang et al ${ }^{[19]}$ found that mechanical ectopic pain, depression-like behavior in cyp-induced in a mouse model of TNF- / NFinduced cystitis by inhibition of P- $\mathrm{kB}$ signaling. This study found that P53 pathway downregulation after alpha1 $\mathrm{H}$ treatment indicates the decreased proliferative capacity of tumor cells and the IL- 6 / Stat3 axis and TNF- / NF- KB signaling pathway, indicating that the immunoinflammatory response was alleviated in vivo in patients after the use of the new drug alpha1 $\mathrm{H}$.

This study found that some of the genes in the TGF-signaling pathway changed treatment with the new drug alpha1H.Hung Tzong-Tyng et al ${ }^{[20]}$ found that the TGF-pathway is involved in BC progression. BIAN JING et al 24 showed that BC cells utilize mutant TGF-receptors for TGF-signaling, leading to their enhanced migration and invasion, and avoiding growth arrest. Shi Heng et al ${ }^{[21]}$ found that LINC01451 promotes epithelial-mesenchymal transformation through the activation of the LIN28 / TGF- / Smad signaling pathway, thereby aggravating BC progression. Zhu Feng et al ${ }^{[22]}$ found that LncRNA AWPPH can inhibit SMAD4 through EZH2, promote BC cell proliferation, migration, and inhibit apoptosis.SMAD4 levels were downregulated in $\mathrm{BC}$ tissues as compared to normal bladder tissues. The results of this study show that some of the genes in the TGF-signaling pathway have changed after the new drug alpha1H treatment, and that the upregulation of SMAD6 gene expression contributes to patient prognosis, but the upregulation of SMAD4 and SMAD9 genes is instead unfavorable to patient prognosis.

LINC00152 may be involved in cell cycle arrest, apoptosis, epithelial to mesenchymal transformation, cell migration, and may serve as reliable biomarkers for the diagnosis of some cancer types. Tang Xian-li et $\mathrm{al}^{[23]}$ found that Linc00152 is highly expressed in bladder cancer patients, and that the possible oncogenic role of Linc00152 in bladder cancer is achieved through the activation of Wnt / b-Catenin signaling, suggesting that Linc00152 may be a novel biomarker for the diagnosis and prevention of bladder cancer. In this study, the constructed Cox proportional analysis model found that high LINC00152 expression unfavorable patient prognosis, while the new drug alpha1H reduced LINC00152 has a positive effect on the cancer cure.

In this comparative study, differentially expressed genes between BC tissues and BC tissues after placebo treatment. Functional and pathway enrichment analyses of differential genes revealed potential molecular pathways underlying alpha1 $\mathrm{H}$ in multiple signaling for BC. Further combined with analyses, obtaining key LncRNA closely related to the prognosis of $\mathrm{BC}$ patients provide potential targets for subsequent studies on $\mathrm{BC}$ treatment, while elucidating the molecular mechanisms of cancer suppressor in $\mathrm{BC}$ patients after alpha1 $\mathrm{H}$ treatment.

\section{Conclusions}

This study reports the relationship between differential genes, IncRNAs, signaling pathways and patient prognosis in bladder cancer after alpha1 $\mathrm{H}$ treatment. Analysis of bladder cancer tissues after alpha1 $\mathrm{H}$ treatment found that 394 genes were significantly up-regulated and 385 genes were significantly downregulated. The up-regulated genes were mainly enriched in signaling pathways regulating stem cell 
pluripotency, TGF-signaling pathways and cell cycle. The down-regulated genes were mainly enriched in MAPK signaling pathway, phagosome and TNF signaling pathway. The up-regulation of SMAD 6 gene expression is helpful for the prognosis of patients, while the up-regulation of SMAD4 and SMAD9 genes is not good for the prognosis of patients; the high expression of LINC00152 is not good for the prognosis of patients, and the new drug alpha1H reducing LINC00152 has a positive effect on cancer cure.

\section{Declarations}

\section{Availability of data and materials}

The sequencing data used and analyzed during the current study are available at the following

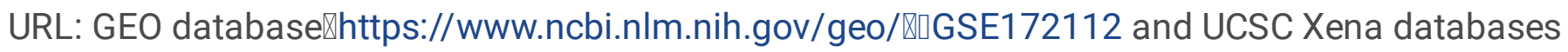

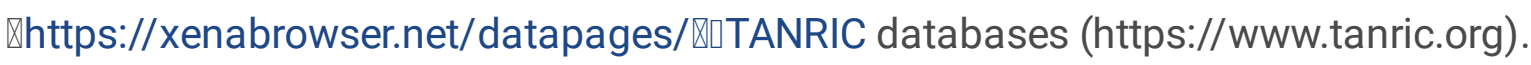

\section{Acknowledgements}

Not applicable.

\section{Funding}

Not applicable

\section{Authors' contributions}

Zhou HY designed the study. Wang X, Yu JD, Wen HL, Wang RJ and Peng K collected and analyzed the data. Wang $X$ wrote the manuscript.

\section{Ethics declarations}

\section{Ethics approval and consent to participate}

Our research have been performed in accordance with the Declaration of Helsinki.

\section{Consent for publication}

Not applicable

\section{Competing interests}


The author declares no conflict of interest.

\section{References}

1. Bray F FJ, Soerjomataram I, et al..Global cancer statistics 2018: GLOBOCAN estimates of incidence and mortality worldwide for 36 cancers in 185 countries[J]..CA: a cancer journal for clinicians,.2018, ;68((6): ):394-424.DOI:10.3322/caac.21492.

2. Kamat A M HNM, Efstathiou J A, et al.Bladder cancer[J].The Lancet, 2016, ;388((10061):): 2796810.DOI:10.1016/S0140-6736(16)30512-8.

3. Saginala K BA, Aluru J S, et al.Epidemiology of bladder cancer[J]..Medical Sciences, .2020, ;8((1): ):15.DOI:10.3390/medsci8010015.

4. Goodison S CM, Dai Y, et al.A multi-analyte assay for the non-invasive detection of bladder cancer[J].PLOS ONE.2012.; 7( 10): e47469. DOI:10.1371/ journal.pone.0047469.

5. Morales A ED, Bruce A W..Intracavitary Bacillus Calmette-Guerin in the treatment of superficial bladder tumors[J]..The Journal of urology, .2002, ;167((2): ):891-4.DOI:10.1016/s00225347(02)80294-4.

6. Hien T T Al, Butler D, et al..Bladder cancer therapy without toxicity-A dose-escalation study of alpha1-oleate[J].International journal of cancer, 2020, 147((9): ):2479-92.DOI:10.1002/ijc.33019.

7. Patel V G OWK, Galsky M D..Treatment of muscle-invasive and advanced bladder cancer in 2020[J]..CA: a cancer journal for clinicians, .2020,; 70((5): ):404-23.DOI:10.3322/caac.21631.

8. Witjes J A BHM, Cathomas R, et al..European association of urology guidelines on muscle-invasive and metastatic bladder cancer: summary of the 2020 guidelines[J]..European urology,.2021, ; 79((1):): 82-104.DOI:10.1016/j.eururo. 2020. 03.055.

9. Feng De Chaobai, Yang Yuyu, and Han Ping. The current status and progress of the diagnosis and treatment of metastatic bladder cancer[J].The Modern Journal of Urology,.2020;25((06):):541-50.

10. Mossberg A K HY, Svensson M, et al..HAMLET treatment delays bladder cancer development[J]..The Journal of urology,.2010, ;183((4): ):1590-7.DOI:10.1016/j.juro. 2009.12.008.

11. Brisuda A HJCS, Kandiyal P S, et al.Bladder cancer therapy using a conformationally fluid tumoricidal peptide complex[J].Nature communications, 2021, ;12((1): ):1-16.DOI:10.1038/s41467021-23748-y.

12. Wu Y ZL, He S, et al.Identification of immune-related LncRNA for predicting prognosis and immunotherapeutic response in bladder cancer[J]..Aging (Albany NY),.2020, ;12((22): ):23306.DOI:10.18632/aging.104115.

13. Li G ZY, Mao J, et al.IncRNA TUC338 is a potential diagnostic biomarker for bladder cancer[J]..Journal of cellular biochemistry, .2019, ;120((10):): 18014-9.DOI:10.1002/jcb.29104.

14. Luo HXC, Le W, et al..IncRNA CASC11 promotes cancer cell proliferation in bladder cancer through miRNA-150[J].Journal of cellular biochemistry,.2019, ;120((8): ):13487-93.DOI:10.1002/jcb.28622. 
15. Ma Z XS, Zeng B, et al.IncRNA SNHG5 is associated with poor prognosis of bladder cancer and promotes bladder cancer cell proliferation through targeting p27[J]..Oncology letters, .2018;; 15((2):): 1924-30.DOI:10.3892/ol.2017.7527.

16. Quan J PX, Zhao L, et al..LncRNA as a diagnostic and prognostic biomarker in bladder cancer: a systematic review and meta-analysis[J].OncoTargets and therapy,.2018, ;11:: 6415.DOI:10.2147/OTT.S167853.

17. Schulz G B ES, Börding T, et al..Therapeutic and prognostic implications of NOTCH and MAPK signaling in bladder cancer[J]..Cancer science, .2021;; 112((5): ):1987.DOI:10.1111/cas.14878.

18. Korac-Prlic J DM, Vilovi ć K, et al..Targeting Stat3 signaling impairs the progression of bladder cancer in a mouse model[J]..Cancer Letters, .2020, ;490:: 89-99.DOI:10.1016/j.canlet.2020.06.018.

19. Chen J L ZX, Liu B L, et al..Normalization of magnesium deficiency attenuated mechanical allodynia, depressive-like behaviors, and memory deficits associated with cyclophosphamide-induced cystitis by inhibiting TNF- $\alpha$ /NF-KB signaling in female rats[J]..Journal of neuroinflammation, .2020;; 17((1):): 1-19.DOI:10.1186/s12974-020-01786-5.

20. Hung T T WH, Kingsley E A, et al..Molecular profiling of bladder cancer: involvement of the TGF- $\beta$ pathway in bladder cancer progression[J]..Cancer letters,.2008;; 265((1): ):2738.DOI:10.1016/j.canlet.2008.02.034.

21. Shi HXJ, Wang K, et al..LINC01451 drives epithelial-mesenchymal transition and progression in bladder cancer cells via LIN28/TGF- $\beta /$ Smad pathway[J]..Cellular Signalling, .2021, ;81: :109932.DOI:10.1016/j.cellsig.2021.109932.

22. Zhu F ZX, Yu Q, et al..Retracted: LncRNA AWPPH inhibits SMAD4 via EZH2 to regulate bladder cancer progression[J]..J Cell Biochem 2018.;119::4496-505. DOI:10.1002/jcb.26556.

23. Xian-Li T HL, Hong Z, et al..Higher expression of Linc00152 promotes bladder cancer proliferation and metastasis by activating the Wnt/ $\beta$-catenin signaling pathway[J].Medical science monitor: international medical journal of experimental and clinical research, .2019, ;25: :3221.DOI:10.12659/MSM.913944.

\section{Figures}




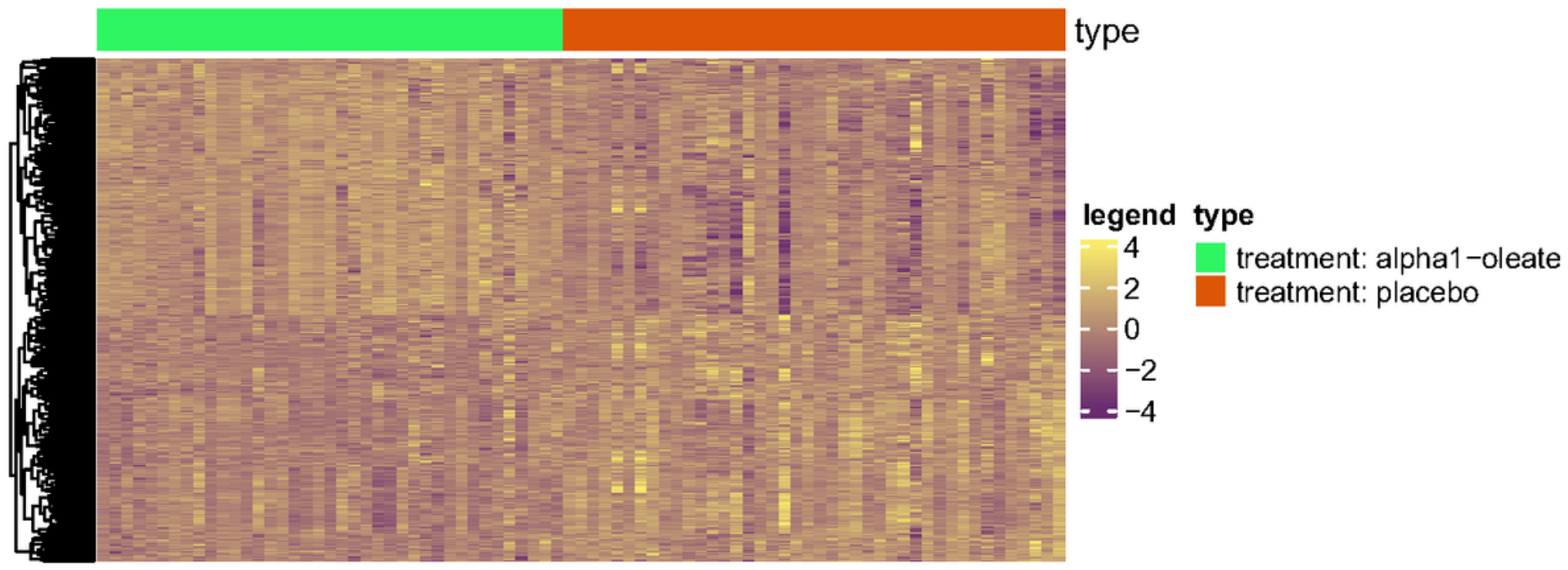

Figure 1

heatmap plot of the overall expression distribution of the 781 differentially expressed genes

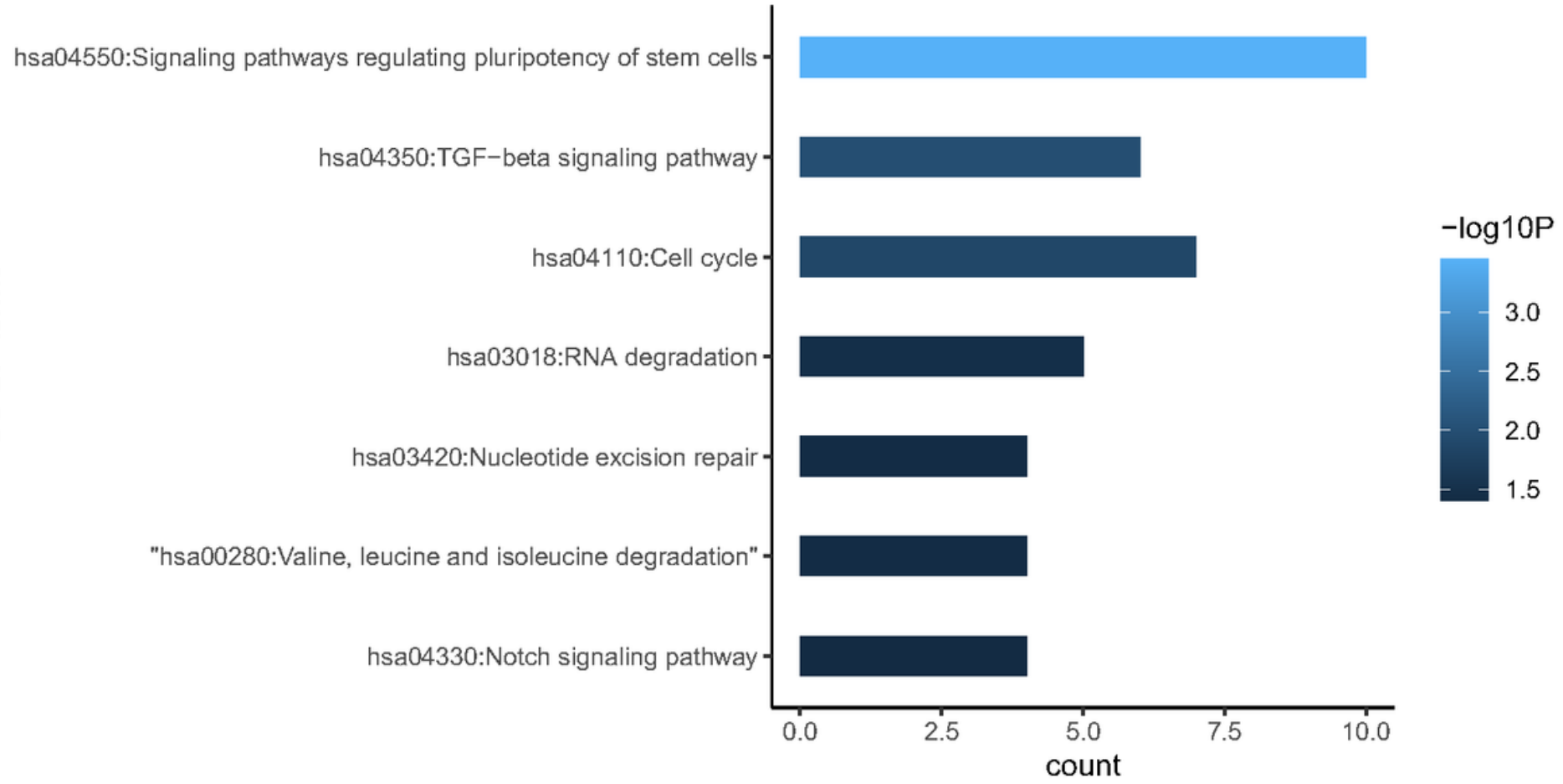

Figure 2

396 KEGG pathway associated with significantly upregulated genes 


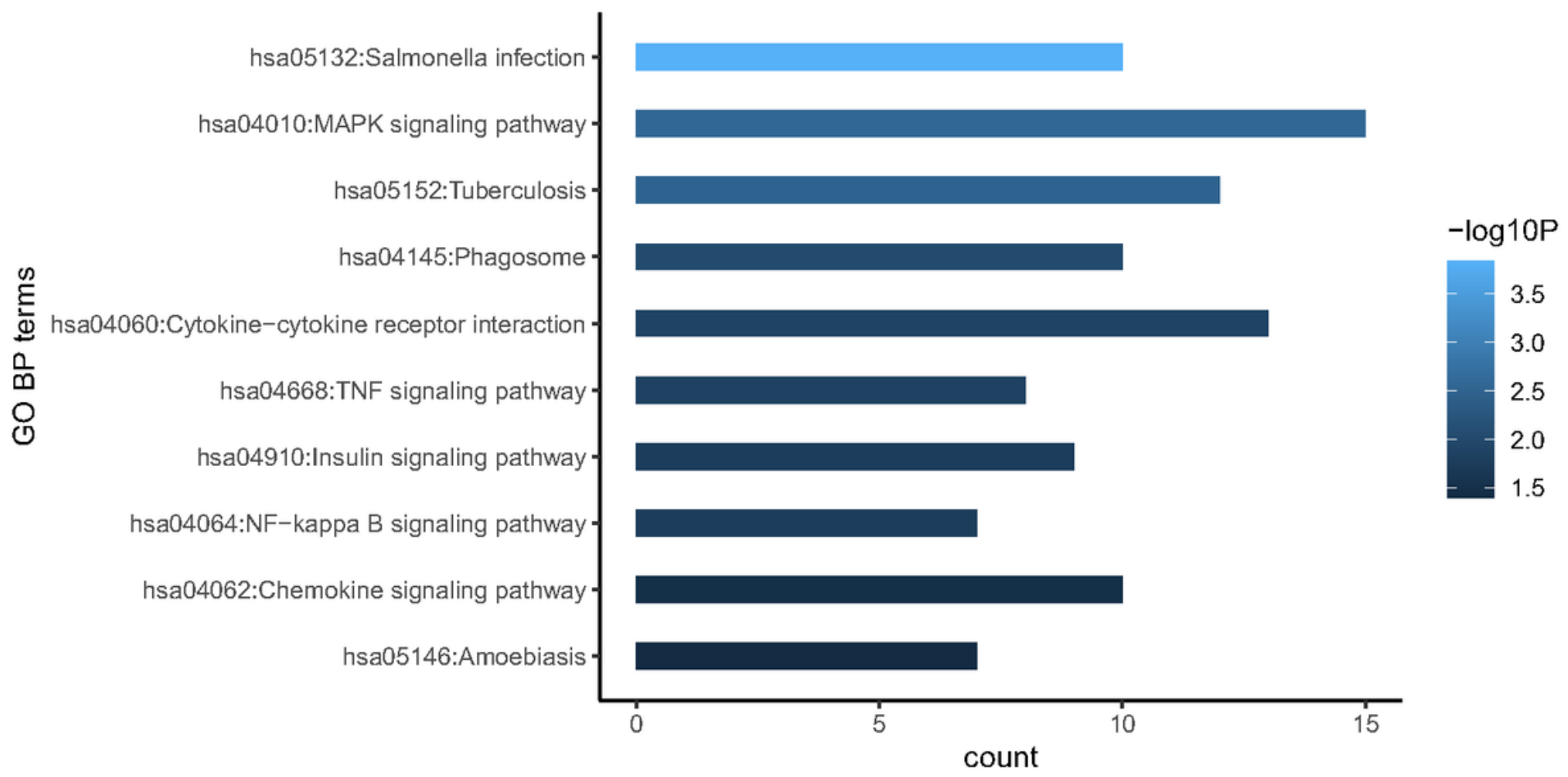

Figure 3

KEGG pathway associated with 385 significantly downregulated genes 


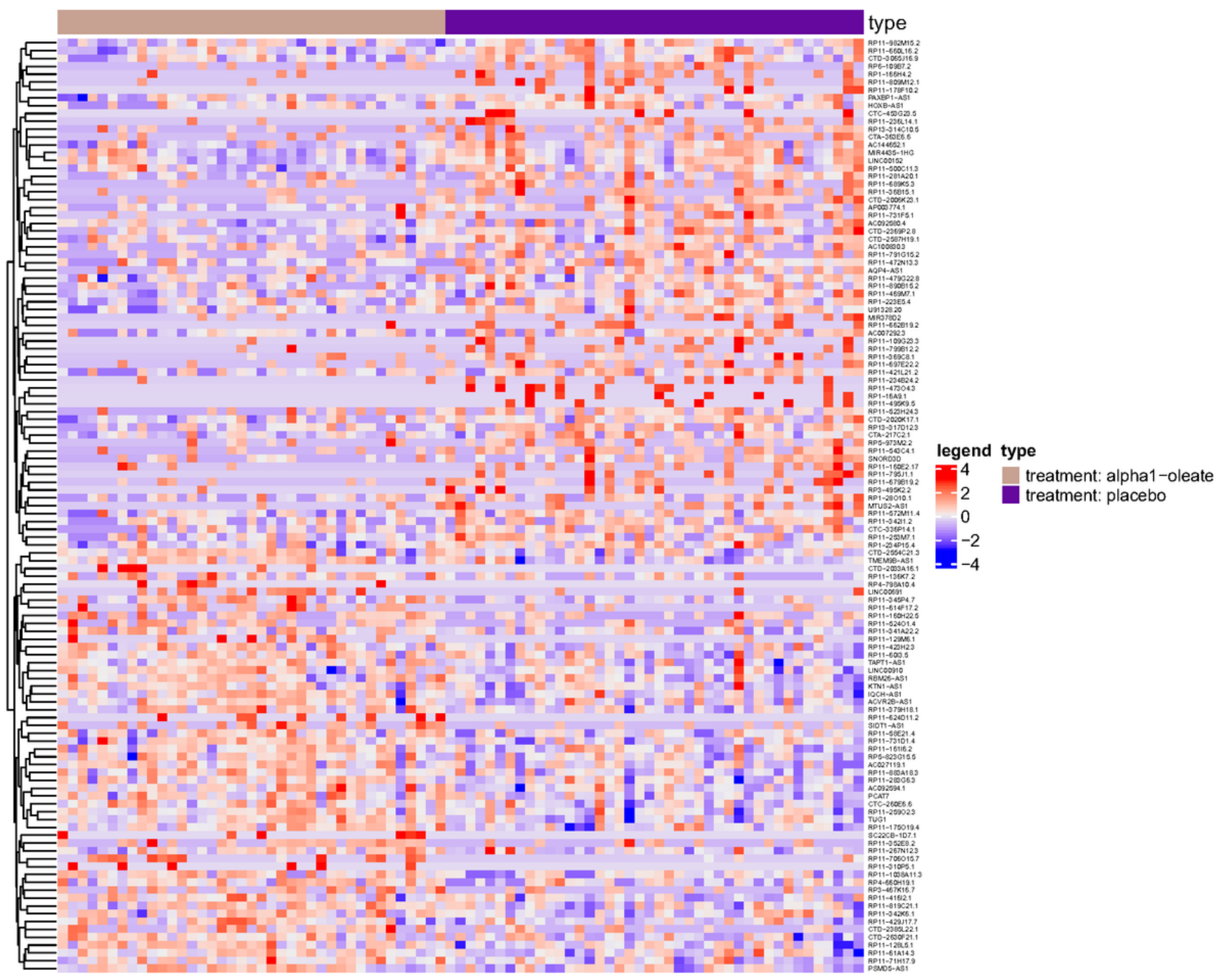

Figure 4

heatmap plot of the overall expression distribution of the 119 differentially expressed IncRNA 


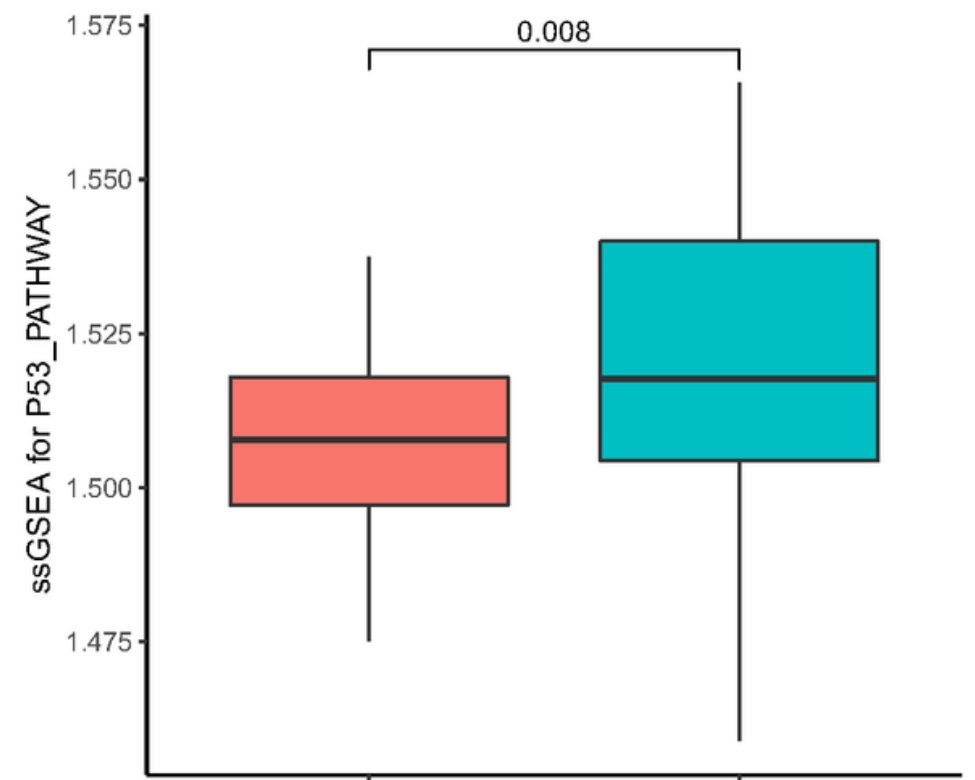

treatment: alpha1-oleate type

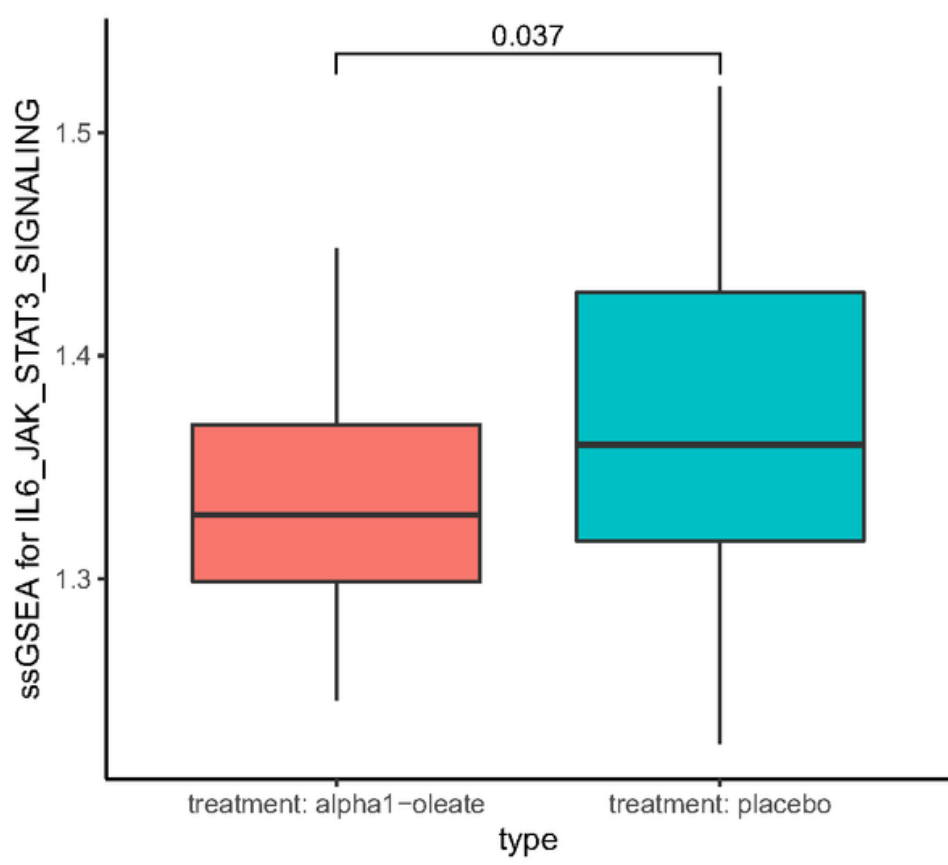

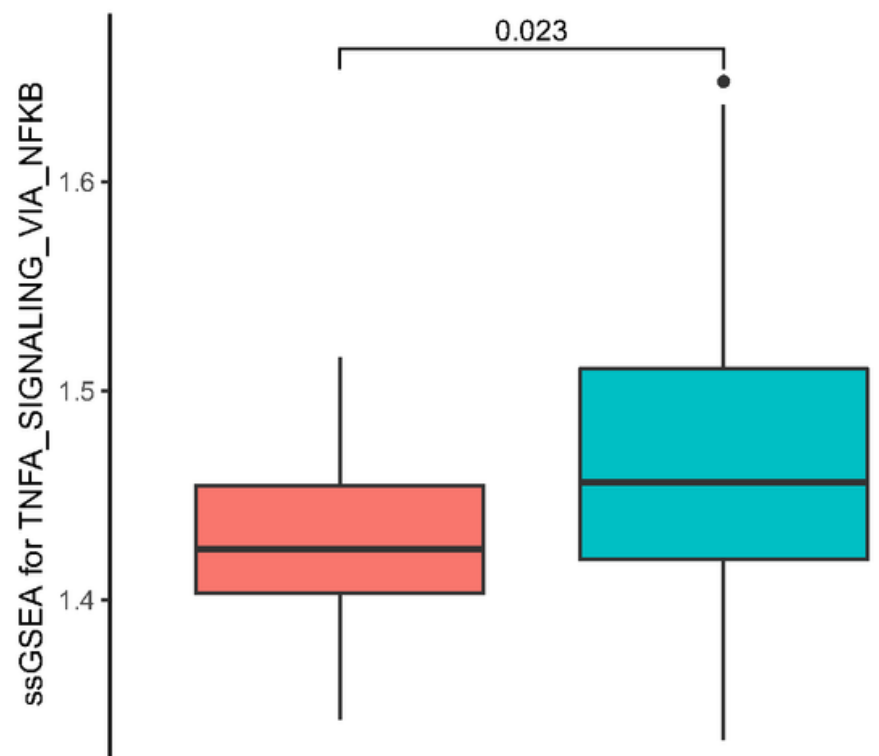

treatment: alpha1-oleate type

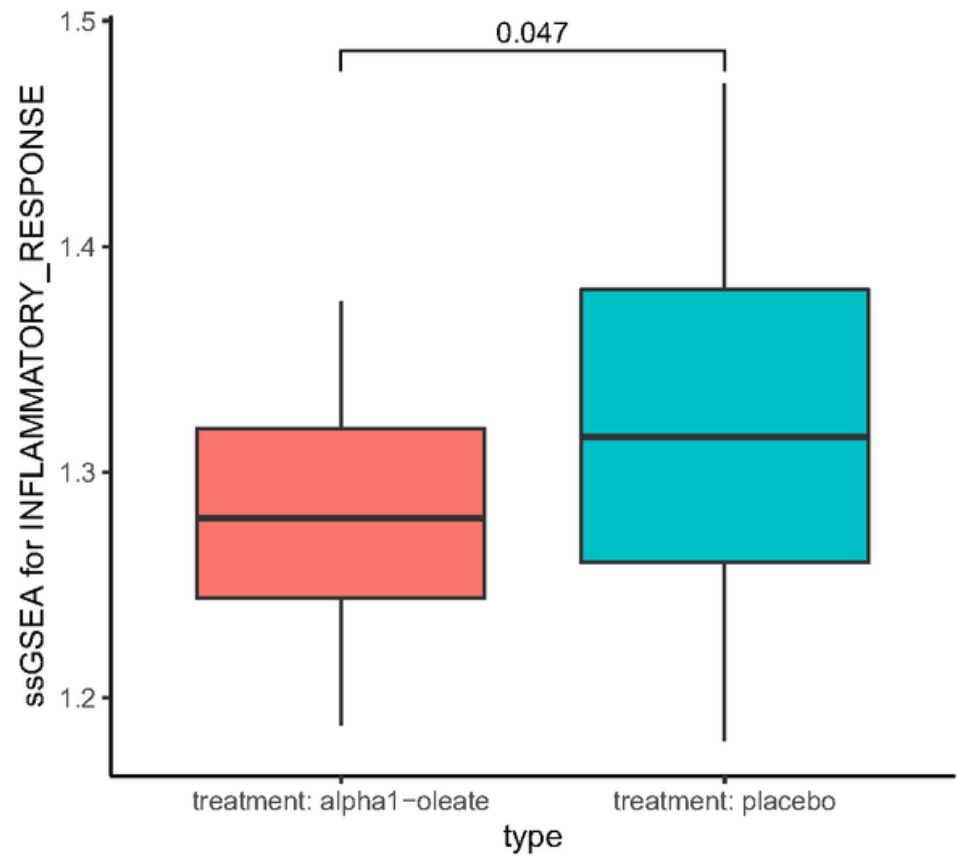

Figure 5

Differential comparison of ssGSEA activation scores for the four important hallmark signaling pathways 
Overall survival

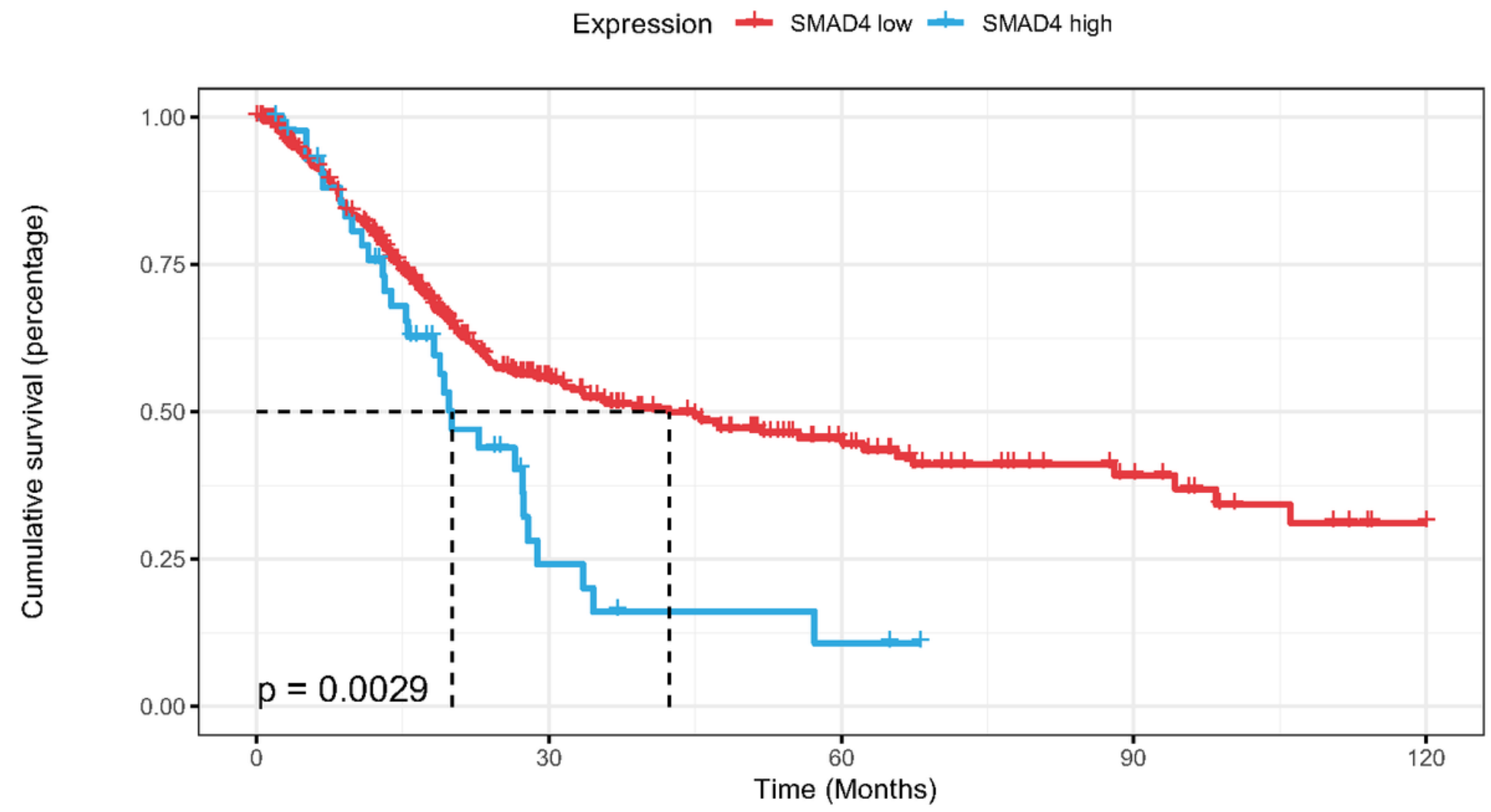

Number at risk

\begin{tabular}{c|ccccc|}
\cline { 2 - 5 } SMAD4low & 381 & 101 & 47 & 19 & 6 \\
SMAD4high & 44 & 6 & 2 & 0 & 0 \\
\cline { 2 - 6 } & & &
\end{tabular}

Figure 6

Overall survival K-M curves of SMAD4 in the TCGA BLCA dataset 
Overall survival

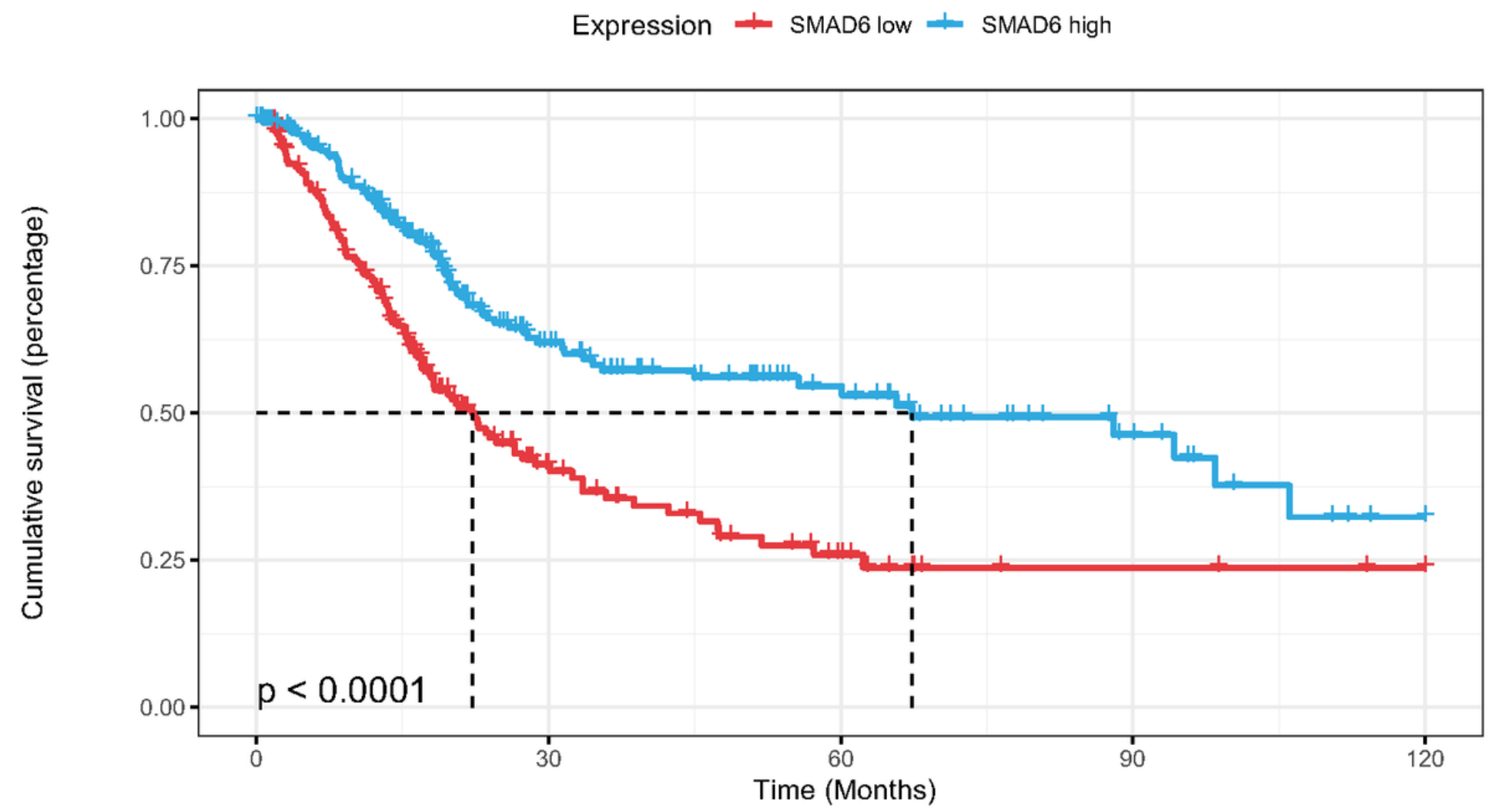

Number at risk

\begin{tabular}{l|lllcl|}
\cline { 2 - 6 } SMAD6low & 188 & 37 & 14 & 5 & 3 \\
SMAD6high & 237 & 70 & 35 & 14 & 3 \\
\cline { 2 - 6 } & & & &
\end{tabular}

Figure 7

Overall survival K-M curves of SMAD6 in the TCGA BLCA dataset 
Overall survival

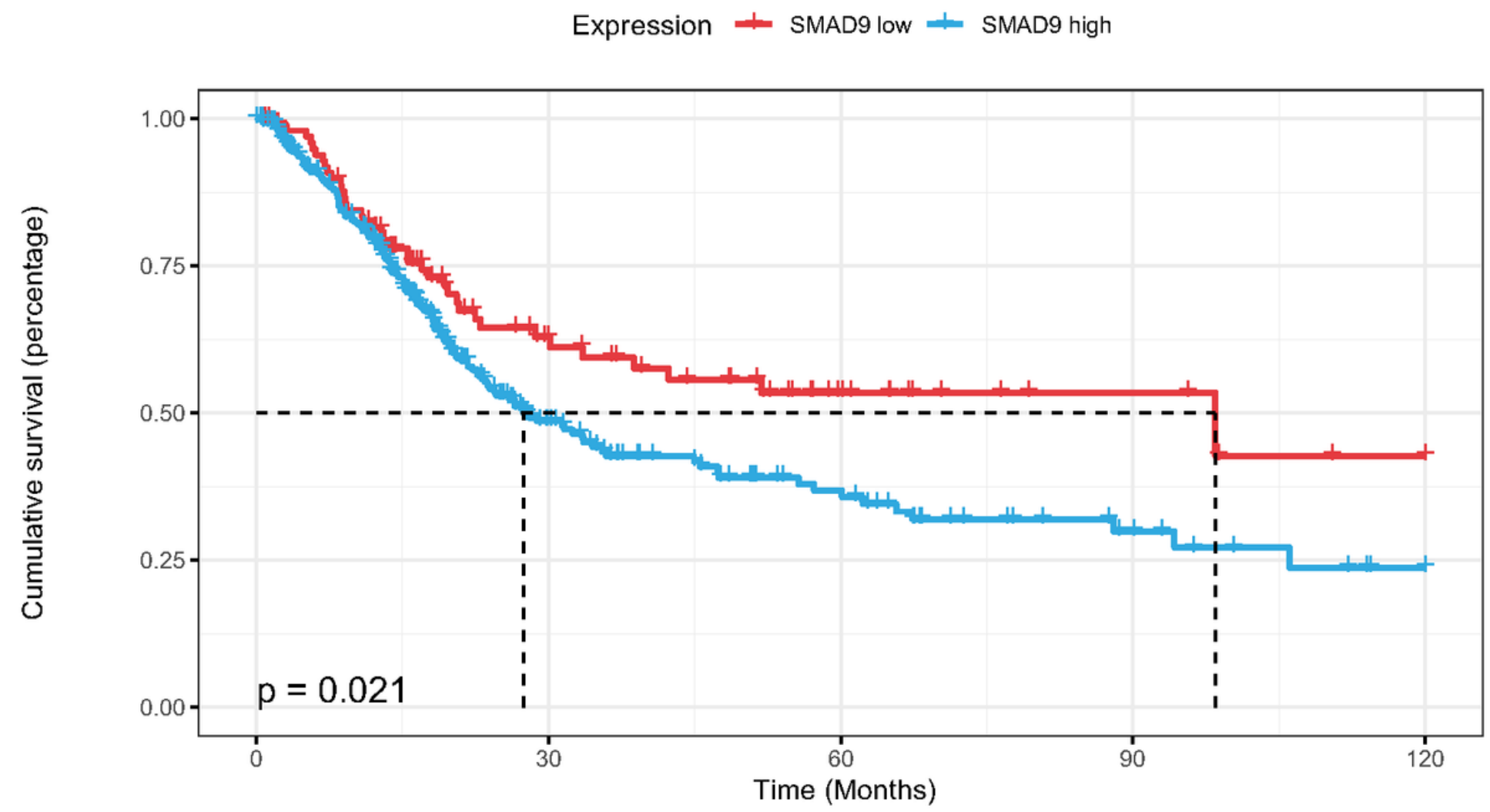

Number at risk

\begin{tabular}{l|ccccc|}
\cline { 2 - 6 } SMAD9low & 102 & 37 & 16 & 6 & 2 \\
SMAD9high & 323 & 70 & 33 & 13 & 4 \\
\cline { 2 - 6 } & & &
\end{tabular}

Figure 8

Overall survival K-M curves of SMAD9 in the TCGA BLCA dataset 
Overall survival

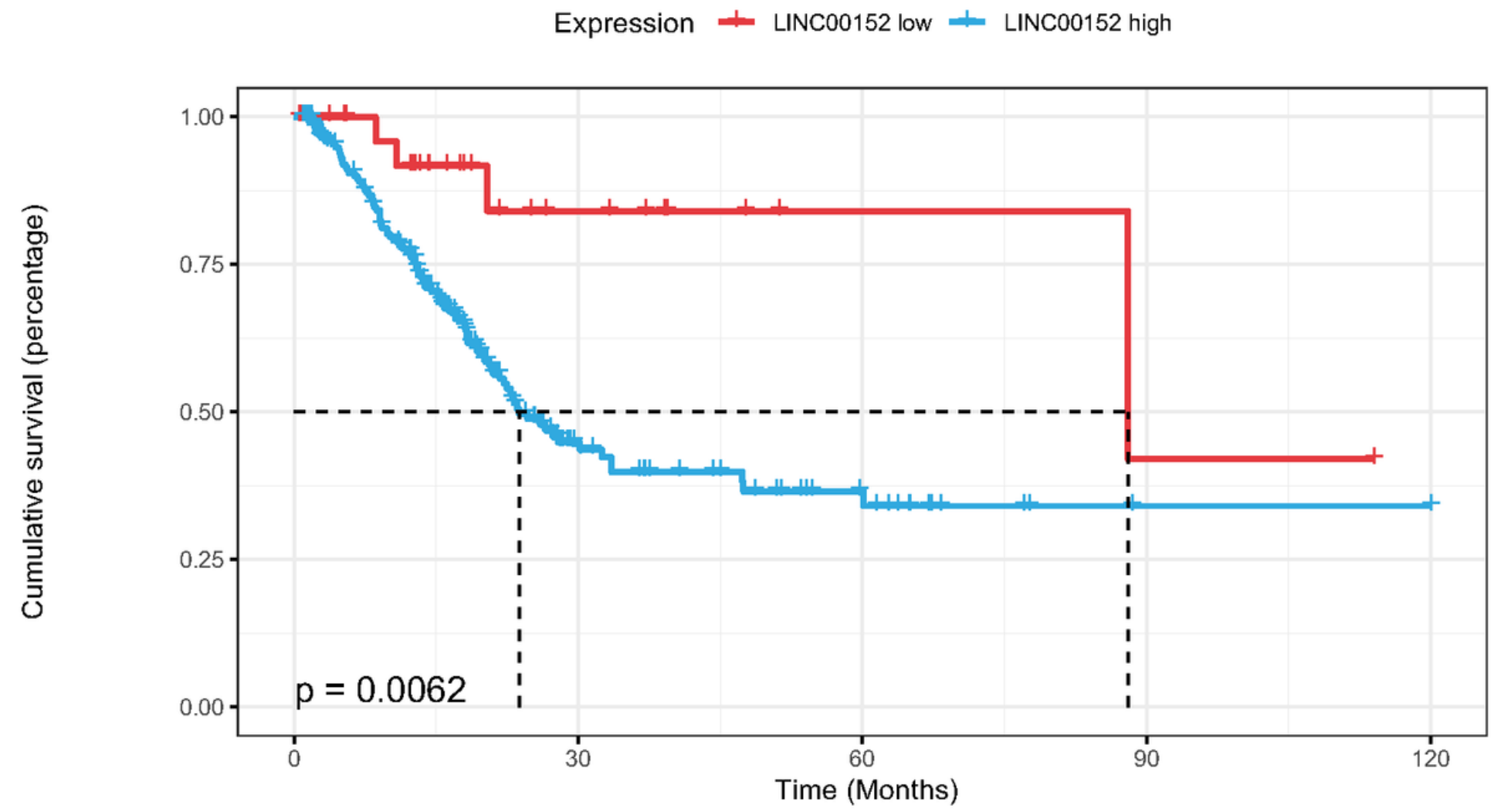

Number at risk

\begin{tabular}{c|ccccc|}
\cline { 2 - 6 } LINC00152low & 30 & 8 & 2 & 1 & 0 \\
LINC00152high & 221 & 37 & 15 & 3 & 3 \\
\cline { 2 - 7 } & & &
\end{tabular}

Figure 9

Overall survival K-M curves of LINC00152 in the TCGA BLCA dataset 